\title{
EDITORIAL
}

\section{ERJ peer reviewers: does this pillar of the Journal's quality need help?}

\author{
G.B. Migliori*, J.B. Soriano\#, V. Brusasco and A.T. Dinh-Xuan+
}

$\mathbf{T}$ he European Respiratory Journal (ERJ) has a long history of success [1]. This success, which has allowed the Journal to keep its impact factor (IF) above 5 for 5 consecutive years, has been paralleled by the impressive growth of the European Respiratory Society (ERS) and its membership [2]. No doubt, a strong society needs a strong journal.

In order to be effective, each individual manuscript should have an aim and a perspective. The aims of this Editorial are to explain to the ERJ readers why peer review is so important to the determination of Journal quality, and to present our needs in terms of reviewers' services. This exercise will be conducted from a reader's point of view first, then from an author's and the Journal's.

Any given reader is interested in having the best manuscripts published in their journal. So, what defines a good manuscript? The manuscript should contain true data and novel information, should be easy to read and, ideally, should provide useful support for the reader's clinical or scientific research activity. This means that a careful selection process needs to be performed at the Editorial level.

For the last 3 years, the ERJ has received an average of $>2,000$ manuscripts annually, covering all areas of respiratory medicine. Only $18 \%$ of these manuscripts have been published in the Journal. How is this process organised? Although largely imperfect, peer review is widely considered to be the best way of assessing scientific merit [3-5]. A difficult obstacle race with scrupulous scientific criteria has been designed to select the best manuscripts; the Chief Editors are responsible for this process, with the collaboration of the Editorial Board. After administrative checks performed by the Publications Office, the Chief Editors perform a first-screening, instantly rejecting $8 \%$ of submitted manuscripts. The remaining manuscripts are electronically sent to the relevant Associate Editor (AE) who oversees their area of interest for the Journal. The AE performs a further screening, leading to the rejection of an additional $28 \%$ of manuscripts without peer review. The remaining $64 \%$

*WHO Collaborating Centre for TB and Lung Diseases, Fondazione S. Maugeri, Care and Research Institute, Tradate. "Dept of Internal Medicine, Medical School, University of Genoa, Genoa, Italy. ${ }^{\#}$ Epidemiology and Clinical Research, CIMERA, Bunyola, Spain. ${ }^{+}$Dept of Cardiopulmonary Medicine, Cochin Hospital, University Paris Descartes, Paris, France.

CORRESPONDENCE: A.T. Dinh-Xuan, Service de Physiologie-Explorations Fonctionnelles, Hôpital Cochin, 27, rue du faubourg Saint-Jacques, 75104 Paris, France. E-mail: anh-tuan.dinhxuan@cch.aphp.fr are sent to expert reviewers for peer review; each manuscript is sent to two reviewers or more, from different areas in terms of background and geography. If the peer-review request is accepted, reviewers have 2 weeks to provide their comments to the AEs, who, based on at least two expert reviewers' opinions, formulate a proposal for rejection, revision or acceptance. This is then discussed within the Editorial Board and the recommendation is approved/disapproved by the Chief Editors.

The expert reviewers are, in essence, in charge of assessing the quality of the manuscript; this includes the amount of novel information provided, the adequacy of the methods to answer the question posed in the introduction, the consistency of data provided, the way the results are discussed, and the correspondence between the evidence provided and the conclusions, both quantitatively and qualitatively. And last but not least, the reviewers contribute to improving the way the manuscript is written, with the readers' perspective in mind.

The author of an original manuscript has his/her own expectations. An author's selection of the journal they will submit to is based on a number of different criteria, including the publication's quality (of which the IF is just one of the elements) [3], and its average response and publication time. The aims of authors of grant proposals, oral presentations and manuscripts also differ. Sequentially, the first wants to obtain funding, the second wants to convince the audience, while the third hopes to have their manuscript revised, accepted and published in a reasonable time.

What is a reasonable time? The reviewer has the previously mentioned 2 weeks to provide their review, although this deadline can be extended in individual cases. But there are also other time considerations: the administrative time (a few days) at the beginning of the process, the time it takes the AE to select at least two reviewers, the time the AE takes to propose the verdict, and the time the Chief Editors need to determine the final verdict. If the manuscript is subject to revision (sometimes more than one), additional time is added. For this reason, the "response time" for the ERJ and other journals can be as long as a few months.

The ERJ has made a special effort to reduce decision times. The median time needed to reach a first decision for all manuscripts is currently 20 days. For the $36 \%$ of manuscripts that obtain an immediate decision, the usual time necessary for different members of the Editorial Board to make the decision to either reject or accept without external reviews ranges from 
1 to 8 days (with the median decision time being $<48 \mathrm{~h}$ ). Finally, authors of the remaining $64 \%$ of manuscripts that are sent out to external reviewers, usually receive a notification from the ERJ's Chief Editors within 4 weeks (median 27 days, range 19-43 days).

Should the ERJ wish to grow further, it needs to attract highquality manuscripts, select the best from these (which are likely to be quoted to further increase the IF and the visibility of the Journal) and do this within the shortest possible time. The bottleneck of the process is the selection of reviewers. The more manuscripts we receive, the more reviewers are needed. The usual, well-known reviewers are subject to burn-out, as they are literally bombarded by review requests, with many of them also acting as AEs or reviewers for other major journals. So the work ERJ reviewers do, on a fully voluntary basis, is really impressive. In 2010, 1,767 reviewers served the Journal [6]. But what happens during vacation time, e.g. from the end of June to early September or from early December to the end of January? More and more reviewers are overstretched and decline review requests, obliging the AEs to either find new reviewers or ask responsive reviewers to do more; meanwhile, the first verdict time increases.

In order to better understand what can be done to improve the situation for readers, authors and the AEs, an exploratory analysis was performed on ERJ Manuscript Central (the Journal's online submission platform; http://mc.manuscriptcentral.com/erj). The analysis demonstrated the following. 1) The time necessary to review an article is small and decreases when the number of manuscripts increases (with a mean difference of 1.3 days for $\geqslant 15$ manuscripts per reviewer per year). 2) Reviewers who are more prone to decline review requests take longer to answer. 3) The vast majority of reviewers perform few reviews, while a relatively small team (just 245!) perform $>15$ reviews each per year. This means two populations of reviewers seem to exist: those who are very faithful to the Journal, performing many reviews and not declining, and those who perform few reviews and are more prone to decline.

Based on these findings, the Journal has committed to identifying new strategies to attract reviewers. They include the possibility of awarding reviewers with continuing medical education (CME) credits granted by the European Board for Accreditation in Pneumology (EBAP) and giving prizes to the top performing reviewers (e.g. free registration to an ERS Congress, a diploma and an invitation to the Editorial Board Dinner).

In order to enrol new, young and motivated scientists in ERJ peer review, we plan to publish a roster of young reviewers who AEs can invite to review on the ERS website.

A special training course for young reviewers has been organised, in collaboration with the ERS School, and will be held at the 2011 ERS Congress in Amsterdam. Its aim will be to provide invited young reviewers with the practical training they need to perform a quality review for the ERJ. The process of identifying young reviewers to invite has already commenced. In addition, a Lunchtime Symposium session specifically devoted to peer review and aimed at a larger audience has also been proposed to the Scientific Committee with the aim of holding this during the ERS Congress in Amsterdam. The course and symposium have been coordinated with the training initiatives planned by the ERS School, which are related to the European MD PhD programme and which also include a component on peer review [7].

If we want a stronger Journal (and we definitely do!), we need to be fully committed to supporting it. There are many ways in which we can all do this. The reader: by reading the ERJ, advocating for it and looking for new ERS members (with the senior-junior approach being very important). The author: by choosing the ERJ for the submission of his/her best manuscripts and by quoting all relevant, recent ERJ manuscripts in their submissions. The reviewer: by accepting review invitations when proposed and by providing quick, high-quality reviews. In this area, new technologies and on open-peer review system could also be considered in the future [8]. The Journal (all of us, who come under the umbrella of the Chief Editors and Editorial Board): by supporting the initiatives mentioned above. And last but not least, the ERS: by continuing its outstanding support of the Society's Journal.

\section{STATEMENT OF INTEREST}

None declared.

\section{ACKNOWLEDGEMENTS}

The authors wish to thank G. Sotgiu (University of Sassari, Sassari, Italy) for his support in performing the statistical analysis.

\section{REFERENCES}

1 Dinh-Xuan AT, Brusasco V. The ERJ in its 21st year of age: a smooth transition for an everlasting evolution. Eur Respir J 2009; 33: 1-2.

2 Siafakas NM. The European Respiratory Society, 1990-2010: a 20year anniversary story of success. Eur Respir J 2010; 35: 1-2.

3 Dinh-Xuan AT, Brusasco V. Refining the changes. Or, how to modify the shape, not the spirit. Eur Respir J 2009; 34: 1.

4 Campion EW, Drazen JM. Peer review journals in the digital age. Arch Bronconeumol 2010; 46: 569-570.

5 Curfman GD, Morrissey S, Annas GJ, et al. Peer review in the balance. N Engl J Med 2008; 358: 2276-2277.

6 List of reviewers. Eur Respir J 2011; 37: 728-734.

7 Eickelberg O, Laurent G, Nicod LP, et al. European Respiratory Society MD PhD programme in respiratory science. Eur Respir J 2010; 36: 229-230.

8 van Rooyen S, Delamothe T, Evans SJ. Effect on peer review of telling reviewers that their signed reviews might be posted on the web: randomised controlled trial. BMJ 2010; 341: c5729. 